\title{
A importância do contador diante do aumento dos índices de microempreendedores individuais inadimplentes: Um estudo nos estados de São Paulo e Paraná
}

\author{
José Antonio Marcelino $^{1}$; Aline Rafaela de Oliveira Sverzuti ${ }^{2}$; Bruna Letícia Gomes da Silva Trizolio ${ }^{3}$
}

\begin{abstract}
Resumo: A figura do microempreendedor individual foi criada em 2008 como uma nova ferramenta para facilitar e incentivar a saída dos trabalhadores da informalidade. O empreendedor que adere ao sistema adquiri algumas obrigações dentre elas o pagamento mensal do documento de arrecadação do simples nacional, e a entrega da declaração anual do simples nacional. Este artigo objetiva analisar o histórico de inadimplência dos últimos cinco anos dos microempreendedores individuais dos estado de São Paulo e Paraná de modo a compreender sua evolução, relação e influência no cenário econômico brasileiro, e apresentar o profissional contábil como fonte para melhorar a adimplência e o desenvolvimento dos negócios. A metodologia de pesquisa é definida como descritiva, explicativa e quantitativa sendo elaborada através de pesquisas bibliográfica em artigos online e sites. Os resultados demonstraram que as taxas de inadimplência são altas em ambos mas que o estado de São Paulo apresenta um índice mais altos o estado do Paraná. Através das pesquisas bibliográficas constatou-se a relevância da Contabilidade para os MEIs visto que esses profissionais auxiliam na elaboração de planejamento estratégicos, na escrituração das movimentações financeiras, na análise de viabilidade do negócio e em muitos outros aspectos. Por fim, concluiu-se que a contabilidade possibilita aos MEIs alcançar o sucesso por meio do gerenciamento apropriado de sua empresa.
\end{abstract}

Palavras-chave: Microempreendedor individual, inadimplência e ciência contábil.

\section{The importance of the accountant in the face of the increase in defaulting individual microentrepreneurs: A study in the states of São Paulo and Paraná}

\begin{abstract}
The figure of the individual microentrepreneur was created in 2008 as a new tool to facilitate and encourage workers to leave informality. The entrepreneur who joins the system acquired some obligations, among them the monthly payment of the collection document of the simple national, and the delivery of the annual declaration of the simple national. This article aims to analyze the default history of the last five years of individual microentrepreneurs in the states of São Paulo and Paraná in order to understand their evolution, relationship and influence in the Brazilian economic scenario, and to present the accounting professional as a source to improve compliance and the business development. The research methodology is defined as descriptive, explanatory and quantitative and is elaborated through bibliographic searches in online articles and websites. The results showed that default rates are high in both, but that the state of São Paulo has a higher rate than the state of Paraná. Through bibliographic researches it was found the relevance of Accounting for Individual microentrepreneurs since these professionals assist in the elaboration of strategic planning, in the bookkeeping of financial transactions, in the analysis of business viability and in many other aspects. Finally, it was concluded that accounting enables Individual microentrepreneurs to achieve success through the proper management of their company.
\end{abstract}

Keywords: Individual microentrepreneur, default and accounting science.

\footnotetext{
${ }^{1}$ Bacharel em Ciências Contábeis, Doutorando em Educação (USEK/Chile), professor do Centro de Ciências Sociais Aplicadas do Curso de Ciências Contábeis da Universidade Estadual do Norte do Paraná - (UENP), e-mail: josemarcelino@uenp.edu.br, Cornélio Procópio, Paraná, Brasil;

2 Graduanda em Ciências Contábeis, pela Universidade Estadual do Norte do Paraná - (UENP), e-mail: alinynha.sverzuti@gmail.com, Cornélio Procópio, Paraná, Brasil;

3 Graduanda em Ciências Contábeis, pela Universidade Estadual do Norte do Paraná - (UENP), brunaleticiagomes1@gmail.com, Cornélio Procópio, Paraná, Brasil.
} 


\title{
Introdução
}

O empreendedorismo tem um papel fundamental por possibilitar o desenvolvimento econômico de um país pois é o impulso de criação de novos negócios.

A taxa de empreendedorismo no Brasil atingiu, em 2018, 38\% do TTE (Taxa de Empreendedorismo Total) segundo a pesquisa da Global Entrepreneurship Monitor (2018) esse índice representa que cerca de 52 milhões de brasileiros tinham seu próprio negócio.

O empreendedor é uma pessoa que consegue ver oportunidades onde alguém ainda não viu.

\begin{abstract}
O empreendedor deve ter visão e percepção para identificar as oportunidades. Suas atitudes empreendedoras devem focar as pessoas e não somente as empresas, atitudes estas que são fundamentais para o sucesso ou o fracasso da empresa. (CUSTÓDIO, 2011, p. 12)
\end{abstract}

Logo, é aquele profissional que de forma criativa coloca em prática suas ideias, seja motivado por uma crise ou algo inovador que desenvolveu. Muitas vezes esse empreendedor encontra dificuldades para entrar no mercado, seja para vender essa ideia ou para desenvolver o produto e entregá-lo para o consumidor final, devido ao alto índice burocrático e aos poucos recursos de que disponibiliza.

Entretanto com o surgimento do Microempreendedor Individual (MEI) muitos brasileiros vislumbraram uma oportunidade para abrir o próprio negócio, uma forma de conquistar proventos para a própria manutenção e da família ou mesmo formalizarem um negócio que já possuíam.

A figura do MEI surgiu ao final de 2008 para incentivar as pessoas a saírem da informalidade, abrir sua própria empresa e ao mesmo tempo conquistar alguns benefícios, porém mesmo com as baixas taxas a serem pagas ao governo, o índice de inadimplência desses empreendedores é alto.

Segundo Ferreira (2000, p.379) inadimplência significa "Falta de cumprimento de um contrato ou de qualquer de suas condições", no caso do MEI, segundo o Fenacon (2016) o maior motivo seria o esquecimento ou a dificuldade de imprimir a guia todos os meses para realizar o pagamento.

A taxa de descumprimento das obrigações é alta e esse estudo analisará o histórico de inadimplência dos estados do Paraná e São Paulo dos últimos 5 anos, com o objetivo de compilar as informações sobre esse índice em uma comparação entre os estados e o índice 
nacional, e por fim apresentar a ciência contábil como uma importante ferramenta para a gestão dos micro empreendimento.

Neste contexto, surge questionamento da pesquisa: Qual a importância do contador diante do aumento dos índices de microempreendedores individuais inadimplentes? Para tanto, foi realizado uma pesquisa bibliográfica em sites e livros com o tema relacionado e uma análise dos dados coletados.

A metodologia de pesquisa caracteriza-se como descritiva e explicativa, quantitativa e desenvolvida com pesquisa bibliográfica em artigos online e sites voltados ao microempreendedor, por fim gerou um gráfico exemplificativo em relação as taxas de inadimplência ao longo dos anos analisados, isto posto, descreve-se as funções do profissional contábil e como elas podem melhorar o gerenciamentos de todos os empreendimentos, em especial, os microempreendedores individuais.

\section{Metodologia}

Esta pesquisa classifica-se como aplicada de acordo com Marconi e Lakatos (2002) por visar a geração de conhecimento prático sobre o assunto e na solução dos problemas, seu objetivo é a coleta e análise de dados e de um fenômeno e, portanto, é classificada como descritiva e explicativa, de caráter quantitativo, por conter coleta de dados estatísticos a respeito de um fenômeno.

\footnotetext{
Zanella (2006, apud SILVA, 2015, p. 54), afirma que: Enquanto o método quantitativo de pesquisa preocupa-se com a medição dos dados, o método qualitativo não emprega a teoria estatística para medir ou enumerar os fatos estudados. Preocupase em conhecer a realidade segundo a perspectiva dos sujeitos participantes da pesquisa, sem medir ou utilizar elementos estatísticos para análise dos dados. O método qualitativo de pesquisa não é empregado quando o pesquisador quer saber quantas pessoas têm preferência por um produto, portanto, não é projetado para coletar resultados quantificáveis.
}

$\mathrm{O}$ artigo foi elaborado por meio de um estudo bibliográfico a respeito do microempreendedor em livros, sites e artigos online que tratam sobre a economia e o perfil esses e um levantamento das taxas de inadimplência, encontradas principalmente em reportagens online e sites voltados ao MEIs e utilizou-se de gráficos para a apresentação dos dados coletados. 


\section{Referencial Teórico}

\section{Microempreendedor Individual}

O Microempreendedor individual- MEI foi decretado pela a Lei ${ }^{\circ} 128 / 2008$, com vistas a minimizar os índices de trabalhadores informais, simplificando e desburocratizando as obrigações fiscais em relação as demais figuras empresariais e também garantindo acesso aos benefícios previdenciários.

Para Silva e Marcelino (2019, p.311) afirmam que a criação desse tipo de empresa é uma alternativa para redução da informalidade, a qual pode dar condições do desenvolvimento de novos negócios empreendedores não identificados nas empresas de grande porte.

$\mathrm{Na}$ atualidade encontram-se cadastrados como MEIs mais de 9 milhões de pessoas conforme o Portal do Empreendedor (2020) e essa formalização proporciona aos empreendedores alguns benefícios entre eles a aposentadoria, auxílio doença, auxílio maternidade, emissão de notas fiscais, possibilidade de realizar negócios com o governo, facilidade de crédito, entre outros.

De acordo com o portal do Simples Nacional o MEI- Microempreendedor Individual é a pessoa física que trabalha de forma autônoma e possui um registro no cadastro nacional de pessoas jurídicas, e se enquadra no regime tributário do Simples Nacional, podendo ter um faturamento de até $\mathrm{R} \$ 81.000,00$ por ano ou $\mathrm{R} \$ 6.750,00$ proporcionalmente. A formalização é feita diretamente pela internet no Portal do Empreendedor, no anexo XI da resolução CGSN n ${ }^{\circ}$ 140, de 2018, estão descritas todas as atividades legalmente permitidas para o enquadramento no programa.

O Simples Nacional é um regime tributário diferenciado, simplificado e favorecido previsto na Lei Complementar $n^{\circ}$ 123, de 14.12.2006, segundo o Portal do Simples Nacional.

O Documento de arrecadação do Simples Nacional para os microempreendedores- DAS MEI, é o documento oficial de pagamento das obrigações fiscais, tributárias e previdenciárias, o valor de arrecadação mensal é fixo em $5 \%$ do salário mínimo para a contribuição previdenciária mais os tributos variáveis de acordo com a atividade desenvolvida, na prestação de serviços o valor corresponde a R \$ 5,00 de ISS, R\$1,00 de ICMS se a atividade for de indústria ou comércio e, caso a atividade seja de comércio e prestação de serviços o valor será de R \$ 6,00 (Portal do Empreendedor 2020).

Ou seja, o valor mínimo de contribuição é de: 
$\mathrm{R} \$ 57,25$ (para prestação de serviços)

$\mathrm{R} \$ 53,25$ (para comércio e indústria),

$\mathrm{R} \$ 58,25$ (para comércio e serviços).

De acordo com a Lei Complementar 128/2008 em seu Art. 18-C (BRASIL, 2008).

\begin{abstract}
Observado o disposto no art. 18-A, e seus parágrafos, desta Lei Complementar, poderá se enquadrar como MEI o empresário individual que possua um único empregado que receba exclusivamente 1 (um) salário mínimo ou o piso salarial da categoria profissional, ficando obrigado a recolher as obrigações previdenciárias relativas ao empregado.
\end{abstract}

Entre as obrigações do microempreendedor individual estão o pagamento da DAS mensalmente e a entrega da Declaração Anual do Simples Nacional (DASN-SIMEI), que constará a receita bruta auferida no ano anterior a declaração, e se contratou algum empregado no período.

Buscando compreender a relevância e o perfil do microempreendedor brasileiro analisou-se a evolução do empreendedorismo no país.

\title{
O Empreendedorismo no Brasil
}

Empreendedorismo é a habilidade que uma pessoa possui em reconhecer os problemas e as oportunidades e através dessa visão utilizar recursos para encontrar soluções e transformálos em algo inovador que traga ganhos a sociedade.

Para Dornelas (2008, p.61) “os empreendedores são pessoas ou equipes de pessoas com características especiais, que são visionárias, questionam, ousam, querem algo diferente, que fazem acontecer, ou seja, empreendem".

As definições de empreendedor diferem-se de acordo com a escola e a abordagem utilizada para tal e, por diversas vezes é atrelado a uma visão idealista de que "seus instintos e habilidades pessoais devem ser suficientes para levar o empreendimento ao sucesso, e as técnicas de administração só serviam para compensar a falta de competências naturais dos não empreendedores" (HASHIMOTO, 2013).

Essa corrente de pensamento acaba por distanciar o empreendedorismo e as técnicas clássicas de gestão e controle e transmite uma mensagem de que o empreendedor é alguém com inerência ao sucesso. 
Vasconcellos Filho (1979, p.126) afirma que:

É válido lembrar aos leitores interessados na utilização do planejamento estratégico que, na maioria das vezes, o sucesso dependerá do conhecimento profundo da realidade ambiental pertinente a organização, obtido por meio de uma análise ambiental mais científica e menos baseada em feeling de executivos experientes.

Muito se enfatiza sobre o espírito empreendedor, da visão empreendedora e inovadora mas autores clássicos escrevem sobre a influência positiva e a necessidade de planejamento estratégico para o sucesso de qualquer empreendimento, fato comprovado pela a alta taxa de mortalidade de novos empreendimentos é que o conhecimento técnico sobre a área é mais que essencial na busca por manter e desenvolver um negócio.

Entretanto não existe apenas o empreendedor que vê uma oportunidade e vai em busca de transformá-la e obter seu sucesso, há também o empreendedor por necessidade e uma parte relevante dos MEIs se encaixam nessa perspectiva.

Segundo Hashimoto (2013) “O empreendedor por necessidade é aquele profissional que foi desligado da empresa e não encontra espaço no mercado de trabalho para se recolocar". Por não conseguir se inserir novamente no mercado de trabalho a pessoa acaba optando por se arriscar e abrir o seu próprio negócio. De acordo com o mesmo autor esse é o fator principal para a alta taxa de mortalidade das empresas brasileiras.

De acordo com GEM- Global Entrepreneurship Monitor em 2016 cerca de 57,4\% dos empreendimentos são por oportunidades e $42,4 \%$ por necessidade, a regularidade desse índice é constatado em um estudo divulgado pelo Sebrae (2019) em que $47 \%$ dos novos empreendimentos são abertos por necessidade, ou seja, o índice é alto e muitas vezes os interessados não realizam um estudo de viabilidade do negócio ou mesmo possuem conhecimento sobre as diversas áreas de uma organização como a tributária e a trabalhista.

A partir disso surge a necessidade de estabelecer adequadamente qual o perfil dos microempreendedores individuais, para compreender suas necessidades de seus anseios, no tópico a seguir analisa-se no decorrer dos anos os fatores que influenciam a escolha por essa figura empresarial e quais as características dos empreendedores que a escolheram. 


\section{Resultados e Descobertas}

\section{O Perfil do Microempreendedor Individual}

O gráfico 1 apresenta o nível de escolaridades dos microempreendedores ao longo dos anos de 2015 a 2019, Como pode ser observado o nível mudou ao longo dos anos, em 2015 o nível médio ou técnico completo representavam $42 \%$, enquanto superior incompleto ou mais apenas 20\%, já o ano de 2017 apresentou uma diferença mínima entre os níveis (41\% médio ou técnico completo e $24 \%$ superior incompleto ou mais, e médio ou técnico incompleto $34 \%$ ).

E então, no ano de 2019 o nível de escolaridade médio ou técnico incompleto passa a apresentar a menor taxa entre os demais, mas ainda representando 1/3 dos MEIs formalizados, nos anos analisados há um crescente de empreendedores com ensino superior, ao mesmo tempo em que a maior parte dos empreendedores são de classe média e alta (SEBRAE, 2017), o Sebrae afirma que esse índice é consequência da melhoria do acesso à educação superior da população de baixa renda.

\section{Gráfico 1: NÍVEL DE ESCOLARIDADE DOS MEIS}

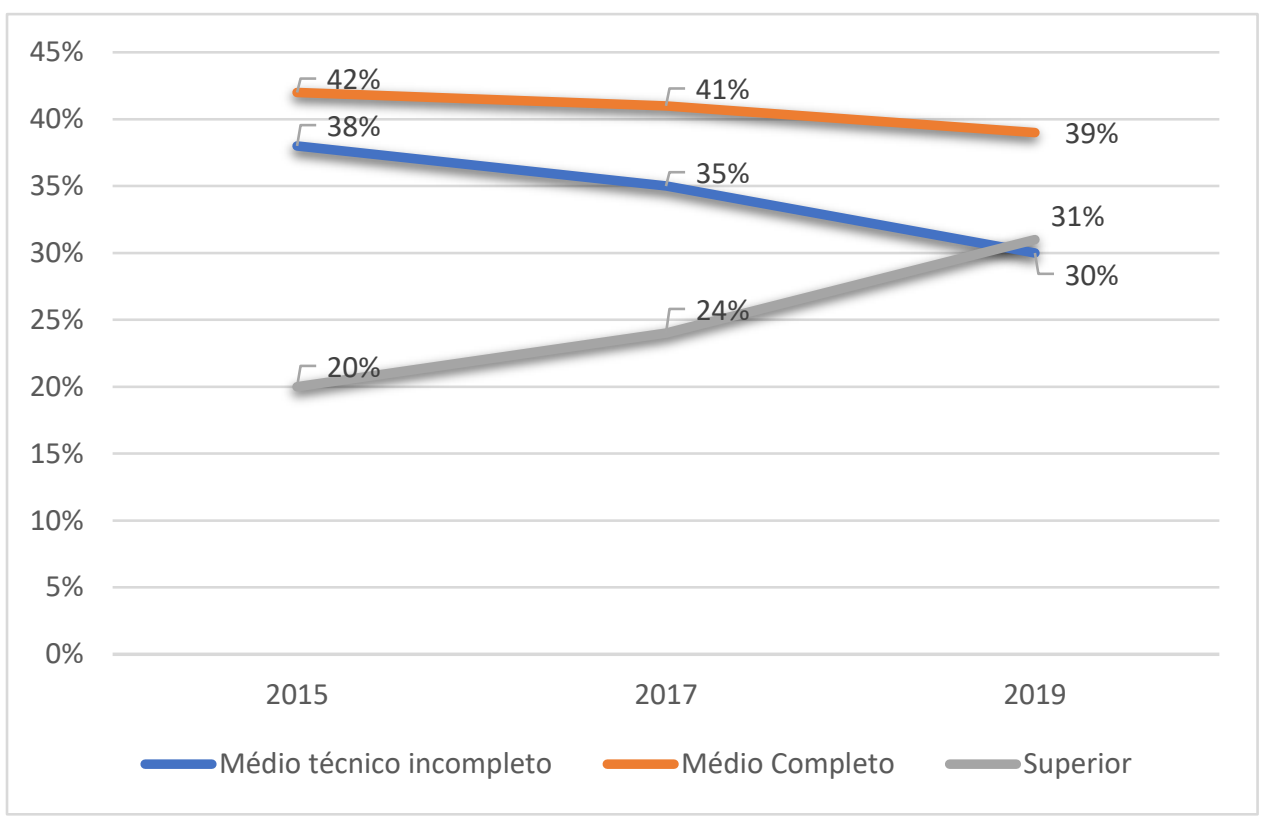

Fonte: Sebrae 2019

De maneira geral, observa-se que os microempreendedores individuais são mais escolarizados que a média da população como aponta a análise do Sebrae (2017). 
Ao verificar a motivação para empreender como microempreendedor nota-se que há uma diferença entre as idades, no aumento da idade dos empreendedores há também uma diminuição do empreendedorismo por independência financeira enquanto o interesse em uma fonte de renda aumenta. Dentre dos anos avaliados não houve mudança significativa entre os fatores motivacionais.

Gráfico 2: Tabela De Motivos Para Empreender Por Idade 2017

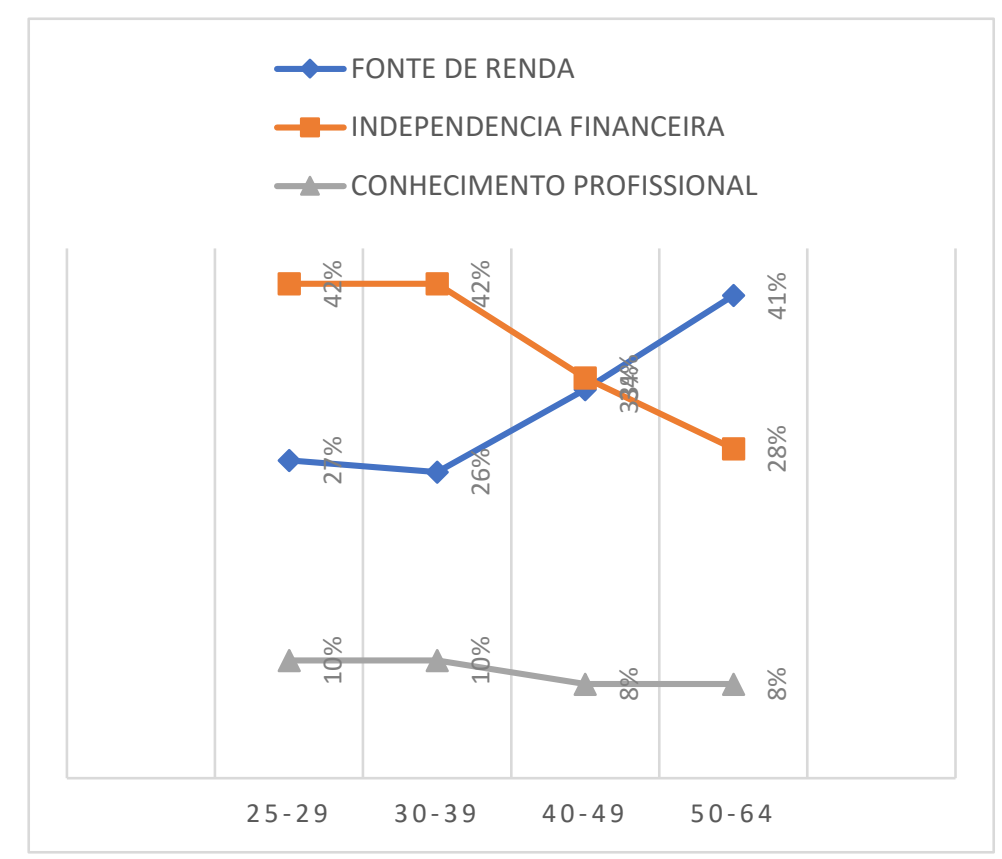

Fonte: Sebrae 2018

Os empreendedores de idades entre 25 e 39 anos buscam principalmente obter independência financeira, mas já na faixa de 40-49 anos entre a independência financeira e a fonte de renda há pouca diferença entre os índices, essa torna-se a principal motivação para as pessoas na faixa etária de 50-64 anos, as mudanças analisadas nos dois anos é explicada pelas faixas etárias mais jovens estarem no início da vida econômica e profissional enquanto a faixa etária mais velha encontra dificuldades de encontrarem posições no mercado de trabalho ao mesmo tempo em que buscam estabilidade para a aposentadoria. 


\section{Gráfico 3: TABELA DE MOTIVOS PARA EMPREENDER POR IDADE 2019}



Fonte: Sebrae 2019

Mas há também uma diferença ente as regiões, de acordo com a pesquisa do Sebrae (2017) a maior parte dos novos empreendedores das regiões sul e sudeste iniciam as atividades como MEI na busca da independência financeira, diferente por exemplo das regiões norte e nordeste, em que a principal motivação é a necessidade de uma fonte de renda.

Os motivos para empreender afetam inadimplência do MEI em cada idade em 2016 o Sebrae (2016) que entre as pessoas entre 20 e 30 anos são os mais inadimplentes e por outro lado tem-se de 50 a 60 anos sendo os com menor índice de inadimplência, o estudo conclui que isso é causa do interesse nos benefícios previdenciários que esses procuram obter.

O gráfico a seguir apresenta ao longo dos anos de 2015 a 2019 uma representação dos setores que os microempreendedores estão atuando. 


\section{Gráfico 4: NÚMERO DE MEI POR SETOR DE ATIVIDADE 2015-2019}

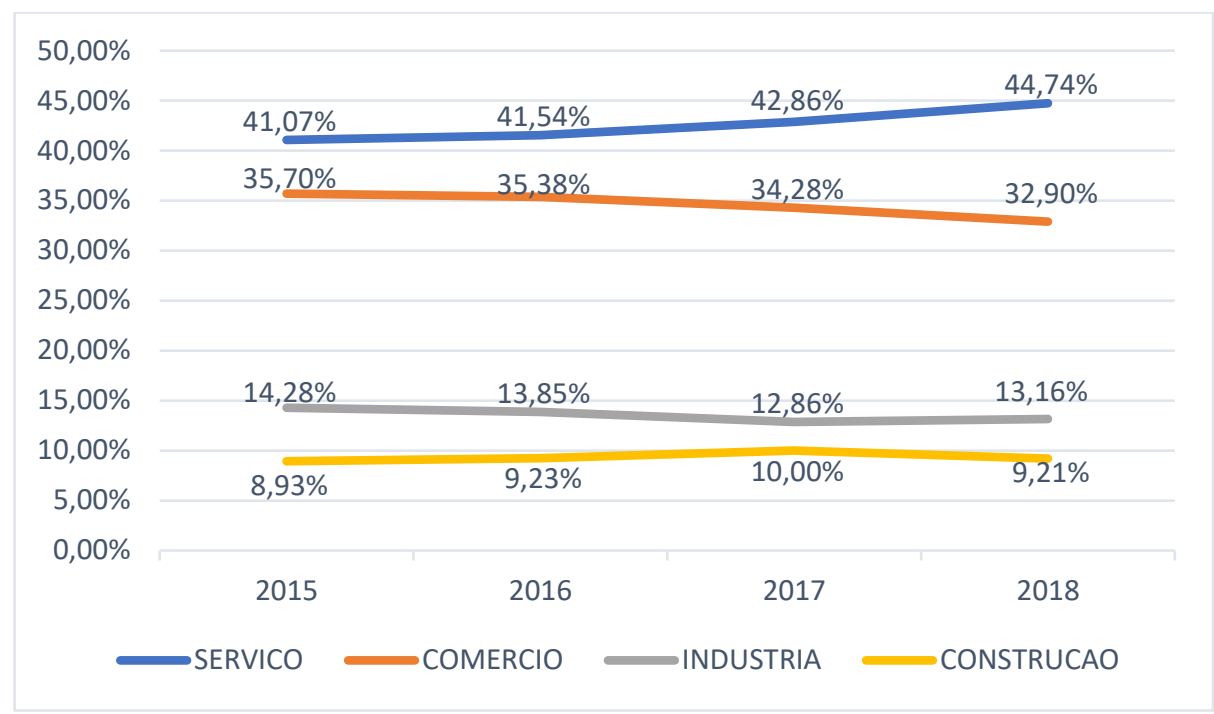

Fonte: Sebrae 2019 (modificado)

A partir da análise observa-se uma clara preferência dos microempreendedores que estão em sua maioria no setor que ao longo dos anos sempre esteve superior a $40 \%$ o de prestação de serviços, nota-se uma pequena queda nas taxas do comércio, mas que permanece representando uma parte maior que indústria e construção juntas.

Nos gráficos a seguir estão representadas as atividades mais frequentemente desenvolvidas pelos microempreendedores individuais nos estados de São Paulo e Paraná.

\section{Gráfico 5: ATIVIDADES DO MEI MAIS FREQUENTES EM SÃO PAULO}

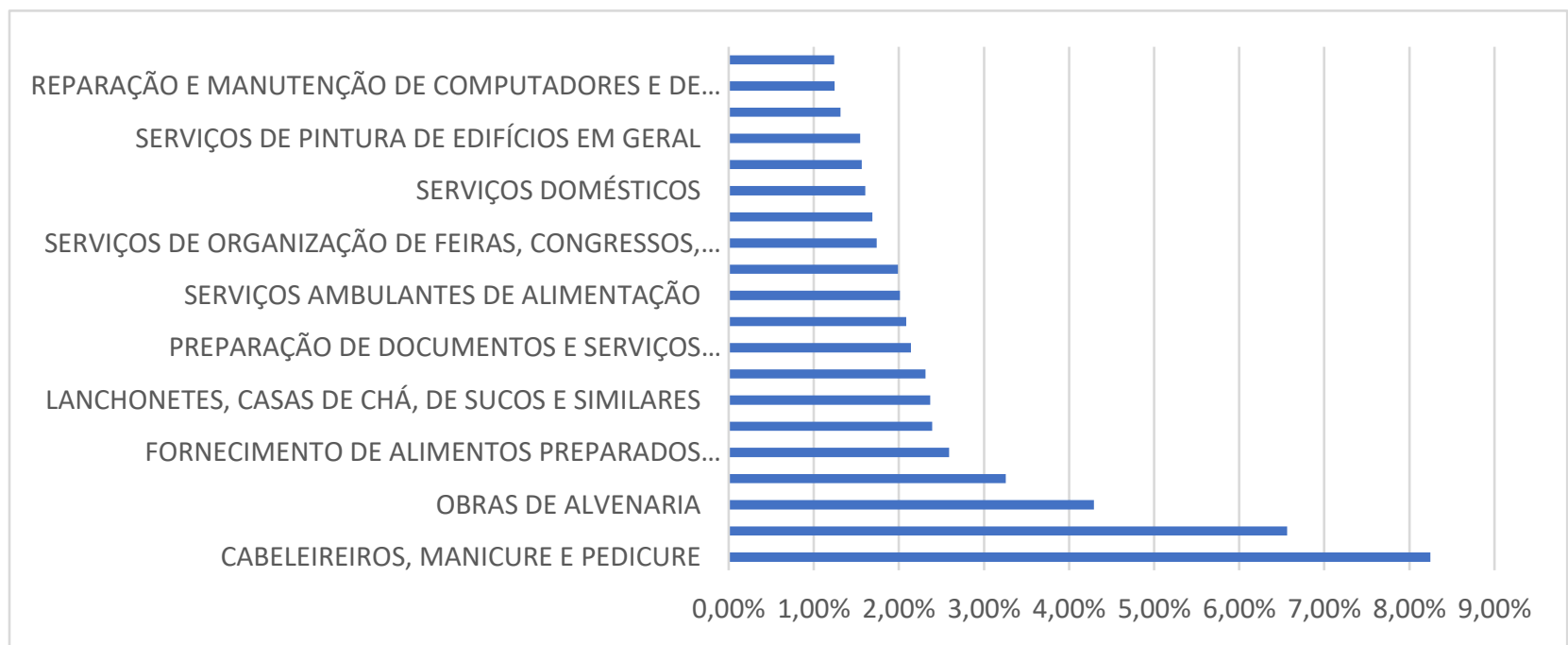

Fonte: Portal do Empreendedor 2020 


\section{Gráfico 6: ATIVIDADES DO MEI MAIS FREQUENTES NO PARANA}

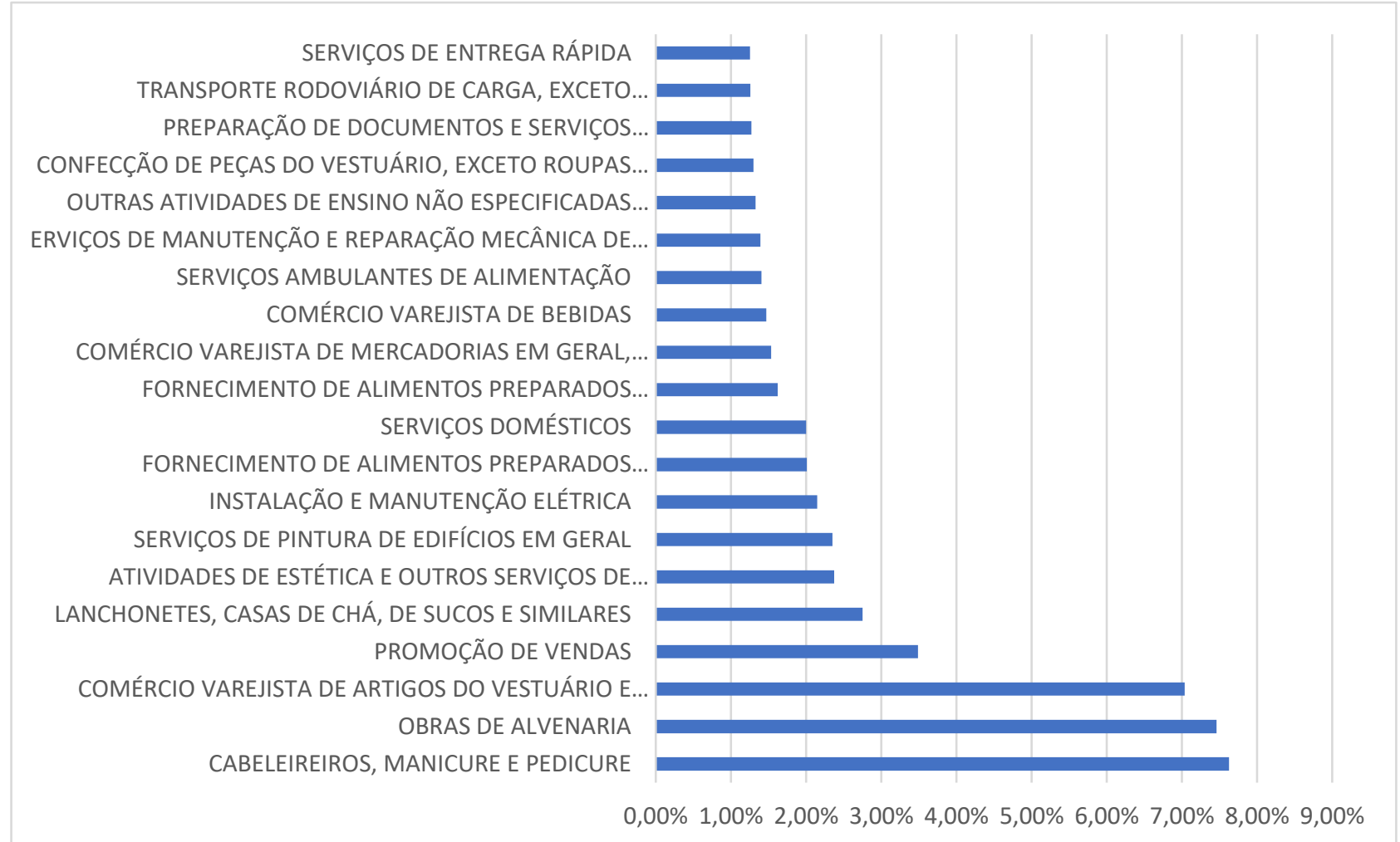

Fonte: Portal do Empreendedor 2020

Em ambos os serviços a prestação de serviço de cabeleireiros, manicure e pedicure são os mais realizados, seguidos por obras de alvenaria e comércio varejista de artigos de vestuário e acessórios. Apesar das outras atividades apresentarem-se como mais ou menos utilizadas não há diferença significativa de um estado para outro.

O fato de nos dois estados não haver uma atividade específica que abranja uma maioria significativa dos empreendedores aponta que o MEI é uma alternativa para os mais diversos negócios.

Com a definição do perfil dos empreendedores optantes pelo MEI parte-se para a análise das causas da alta taxa de inadimplência nos estados bem como no Brasil.

\section{A Inadimplência do Microempreendedor Individual}

O número de empreendedores aumentou nos últimos anos impulsionado principalmente pela recessão econômica vivida pelo Brasil a partir de 2015 conforme afirma Mendonça (2018) ao descrever as causas da crise econômico brasileira. 
Tendo em vista a eclosão da crise econômica aconteceu em 2015. Uma análise do endividamento público em setembro de 2015 mostrou que, nos dois próximos anos, haveria uma forte tendência de crescimento da dívida pública. E segundo dados apresentados pelo IBGE (2019) o desemprego atinge 11,9 milhões de pessoas.

De acordo com Serasa Experian (2018) 80,5\% das novas empresas abertas em 2018 eram MEIs, atualmente já somam mais de 9,4 milhões de cadastrados (PORTAL DO EMPREENDEDOR, 2020), entretanto, o índice de inobservância aos deveres e exigências legais desses empreendedores é alto, esse estudo tem como objetivo verificar o histórico dessa taxa ao longo dos anos de 2015 a 2019 e realizar uma comparação entre os estados de São Paulo e Paraná e o índice nacional.

A possibilidade de formalizar uma empresa, o custo baixo, e o direito a benefícios previdenciários torna o MEI uma possibilidade atraente para sair da informalidade, essa preferência é clara ao analisar o crescimento de 120\% do MEI desde 2015 (SEBRAE, 2019).

Entretanto os índices de inadimplência dos contribuintes vinculados é um fator preocupante por apresentarem um histórico de não cumprimento de obrigações, o descumprimento com as obrigações acessórias causa ao empreendedor inclusão na dívida ativa com a União e mais dívidas para o MEIs.

A taxa de inadimplência desses empresários refere-se ao não pagamento mensal da DAS e a não entrega da declaração anual de faturamento.

A seguir encontra-se o gráfico com as taxas de inadimplência por estado e do Brasil de 2015-2019.

Gráfico 7- TAXA DE INADIMPLÊNCIA MEI 2015-2019

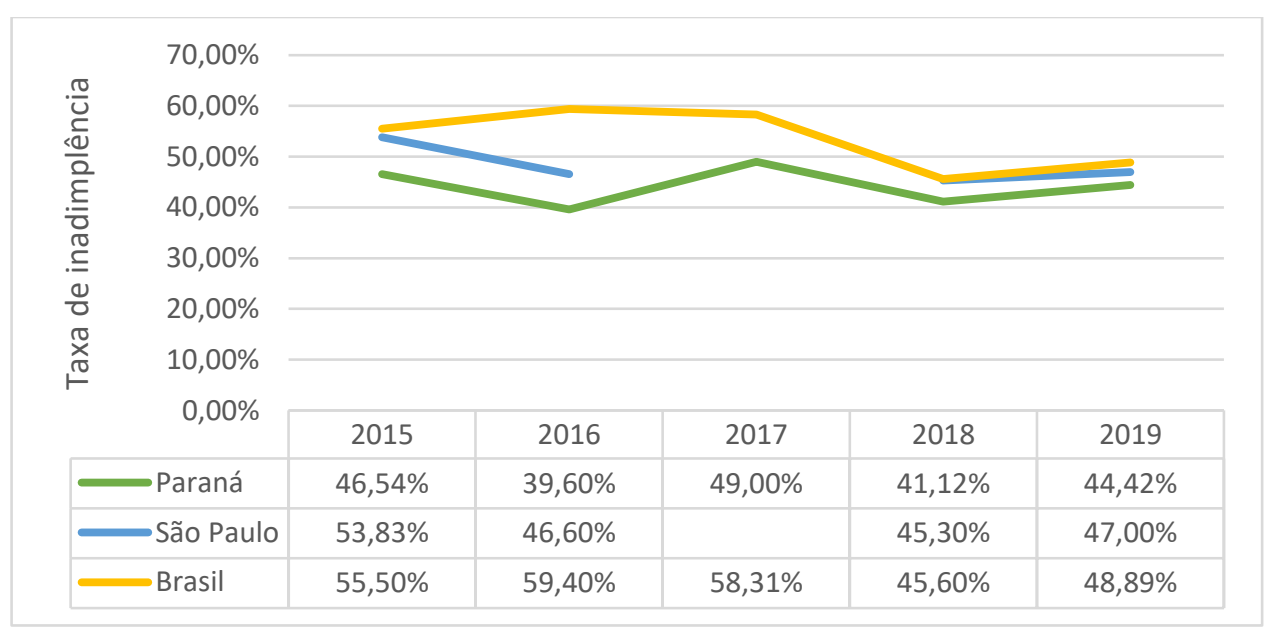

Fonte: Elaborado pelos autores (2020) 
São Paulo é o estado brasileiro com o maior desenvolvimento industrial e o que paga mais impostos a União, de acordo com o Portal do Empreendedor (2020) atualmente existem no estado 2,5 milhões de microempreendedores individuais. No estado do Paraná, mais de 583 mil MEIs estão registrados.

A partir da análise do gráfico 7, observa-se que o índice de inadimplência oscila em todos os anos, e que no estado do Paraná no ano de 2015 para o ano de 2019 houve uma queda de inadimplência de $2,12 \%$, já no estado de São Paulo o índice de inadimplência diminuiu cerca de $6,83 \%$.

O estado de São Paulo tem um histórico de inadimplência maior que o do Paraná em todos os anos avaliados e dentro do maior índice de inadimplência do Brasil, registrado no ano de 2016 com 59,4\%, a inadimplência paranaense registrou seu menor índice com pouco mais de $39 \%$.

Durante as pesquisas o número oficial da porcentagem de inadimplência do estado de São Paulo no ano de 2017 não foi encontrado.

Em todos os anos 2018 foi o que apresentou as menores taxas e presume-se que a queda foi uma consequência da ação realizada pela que a Receita Federal em 2018 a qual cancelou cerca de 1,37 milhão MEIs que estavam inadimplentes, este valor representava em torno de $17 \%$ dos MEIs do país.

\section{A Ciência Contábil}

A ciência contábil encontra-se de tal modo desenvolvida que o profissional contábil hoje nas grandes corporações aproxima-se mais da função de auxílio ao gestor da organização, como aquele que possui conhecimento técnico sobre as demonstrações apresentados pelo setor contábil e que irá, no desenvolvimento de um planejamento estratégico, analisar cenários diversos e propor soluções e orientações assertivas.

\footnotetext{
O objetivo da contabilidade Gerencial é atender a todos os aspectos da gestão das entidades onde se torna necessária a informação contábil. Portanto, sua abrangência é a empresa como um todo, desde as suas necessidades estratégicas e de planejamento até as suas necessidades de execução e controle. (PADOVEZE,2012, pág. 17).
}

Entretanto, nas pequenas empresas ocorre o contrário, ou seja, o contador é encarado como um dispêndio e mesmo um agente do fisco que realiza um controle apenas para os pagamentos dos tributos devidos contratam escritórios contábeis pela simples obrigação 
societária, e não tem auxilio em outros fatores como a análise de viabilidade, analise das informações contidas nas demonstrações contábeis, muitas vezes por não solicitarem esses relatórios, ou mesmo por desconhecimento destes.

Fica evidente, portanto, a necessidade de mostrar aos empreendedores a contribuição que o contador pode fornecer ao alcance do sucesso do empreendimento.

\section{Discussões: O Contador e o MEI}

O microempreendedor individual está legalmente desimpedido da escrituração contábil, porém como o descrito acima o auxílio de um contador pode ser a diferença entre o sucesso e o fracasso de um empreendimento.

Estes profissionais contábeis auxiliam as empresas estimulando os empresários, a melhorar o seu método de empreender, desenvolvendo habilidades gerenciais, auxiliando também nas tomadas de decisões, através dessas informações, o empresário consegue ter uma noção de como sua empresa está, consegue avaliar sua situação patrimonial, bem como planejar atividades de longo e curto prazo. (MORAIS e FILHO,2018, p.2)

O objetivo da criação do microempreendedor individual era auxiliar as pessoas a saírem da informalidade e fornecer a esses trabalhadores benefícios e garantias, a lei 128/2008 que trata o microempreendedor individual ao dispensá-los da obrigatoriedade da contabilidade formal deixa a cargo do empreendedor contratar um profissional contábil

Entretanto é sabido que este profissional é essencial para a realização de alguns processos técnicos como: registro de faturamento e de funcionários e obrigações que o sucedem, auxílio na tomada de decisões, controles, participação em licitações.

Para os autores Madruga, Colossi e Biazus (2016, p. 187),

O trabalho do contador caracteriza-se por desenvolver controles da área financeira, econômica e patrimonial das entidades jurídicas, mantendo-se atualizado em relação à legislação pertinente, cumprindo prazos e organizando informações de apoio ao processo decisório em tempo hábil.

Além de ser fundamental para desenvolvimento sustentável da empresa desde a sua criação por auxiliar na avaliação de viabilidade do empreendimento, na análise do mercado consumidor e dos recursos necessários e disponíveis para criar o negócio e posteriormente na mudança de regime tributário, os profissionais dessa área auxiliam também os empresários no 
dia-a-dia, desde o controle sobre as compras e vendas, no cálculo de receitas, despesas e lucro de cada venda, e assessora na tomada de decisões sobre o investimento do empreendedor

Mesmo que o contador não seja obrigatório para o MEI esse, portanto, presenta-se como o diferencial de uma empresa ao auxiliar o crescimento dela. Por deter conhecimento científico, compreender os perfis de clientes, as concorrências dos mercados irão auxiliar as empresas a conquistarem os melhores resultados.

\section{Conclusão}

Com o constante crescimento do empreendedorismo informal no Brasil foi necessário a criação de um tipo de empresa que atendesse melhor as necessidades dos microempresários e os incentivassem a realizar a formalização das atividades realizadas a partir disso isso foi criado o microempreendedor individual.

A procura por esse tipo de empresa é elevada por causa da pouca burocracia enfrentada e os benefício e garantias que a informalidade não proporciona a esses trabalhadores, mas MEI além de benefícios adquiri também responsabilidades como o pagamento da DAS (documento oficial de pagamento das obrigações fiscais, tributárias e previdenciárias).

Entretanto o microempreendedor individual não deve focar apenas em realizar a inscrição e pagamento a DAS, mas sim ser um empresário responsável e pensar e planejar o desenvolvimento do empreendimento.

A contabilidade é de suma importância para todas as organizações, por gerar informações importante para a tomada de decisões, os profissionais dessa área estão capacitados a auxiliar os empresários no dia-a-dia, ocasionando assim o sucesso das empresas, sejam elas micro, pequenas ou grandes empresas, por estes e outros motivos o microempreendedor deve buscar orientações com um profissional contábil.

O partir da constatação da importância do MEI na economia e as altas taxas de inadimplência o presente trabalho buscou identificar com um estudo nos estados de São Paulo e Paraná qual possui maior índice de inadimplência e suas causas.

Com a pesquisa verificou-se que o estado de São Paulo em todos os anos avaliados atingiu uma taxa de descumprimento com o pagamento da DAS maior que o estado do Paraná, entretanto também apresentou uma queda maior nas taxas. Pode-se averiguar que o contador 
pode auxiliar no cumprimento das obrigações das empresas e que fornece ao empresário orientações relevantes para o sucesso.

Portanto os objetivos do estudo foram atingidos tendo em vista que as taxas de inadimplência dos estados e do país foram coletadas e comparadas e que a partir das pesquisas bibliográficas apresentou-se os motivos que tornam a ciência contábil uma ferramenta para reduzir a inadimplência e proporcionar o crescimento dos empreendimentos

Para futuros trabalhos sugere-se analisar e comparar outros estados brasileiros, e pesquisar o interesse que os profissionais contábeis possuem em auxiliar os microempreendedores individuais.

\section{Referências}

\section{AGÊNCIA SEBRAE DE NOTÍCIAS. MICROEMPREENDEDORES INDIVIDUAIS JÁ SÃO 65\% DOS PEQUENOS NEGÓCIOS MINEIROS. 2019. Disponível em: https://revistapegn.globo.com/MEI/noticia/2019/05/microempreendedores-individuais-ja-sao-65- dos-pequenos-negocios-mineiros.html. Acesso em: 20 dez. 2019.}

ALVARENA, Darlan. Mais de 3,7 milhões de MEIs estão inadimplentes ou inativos: Fisco prepara $1^{\text {a }}$ leva de cancelamentos por falta de pagamento e omissão. 2016. Disponível em:http://fenacon.org.br/noticias/mais-de-37-milhoes-de-meis-estao-inadimplentes-ou-inati vos1149/. Acesso em: 14 dez. 2019.

BRASIL. LEI COMPLEMENTAR 128, DE 19 DE DEZEMBRO DE 2008. Art. 18. Disponível em: http://www.planalto.gov.br/ccivil_03/leis/lcp/lcp128.htm. Acesso em: 20 de dez. 2019.

Custódio, Telma Padilha. A importância do empreendedorismo como estratégia de negócio. 2011. 60 p. (Administração) - UNISALESIANO, Lins, São Paulo, 2011.

DORNELAS, José. Empreendedorismo corporativo: Como ser um empreendedor, inovar e se diferenciar na sua empresa. 2008. 173p. 2. ed. Rio de Janeiro: Elsevier, 2008.

FERREIRA, Aurélio Buarque de Holanda. Mini Aurélio Século XXI Escolar: O minidicionário da língua portuguesa. Aurélio Buarque de Holanda; coordenação de edição, Margarida dos Anjos, Marina Baird Ferreira; lexicografia, Margaria dos Anjos et al. 4. ed. rev. ampliada. Rio de Janeiro: Nova Fronteira, 2000.

Global Entrepreneurship Monitor. Empreendedorismo no Brasil 2016. Coordenação de Simara Maria de Souza Silveira Greco at al. Curitiba: IBQP, 2017. 208 p. Disponível em: http://ibqp.org.br/wp-content/uploads/2017/07/AF-GEM-Nacional-BAIXA.pdf. Acesso em: 06 jan. 2020 .

GLOBAL ENTREPREUNERSHIP MONITOR. Empreendedorismo no Brasil 2018: Relatório Executivo. 2018. Disponível em: https://datasebrae.com.br/wp-content/uploads/2019/02/RelatórioExecutivo-Brasil-2018-v3-web.pdf. Acesso em: 06 jan. 2020. 
HASHIMOTO, Marcos. Espírito empreendedor nas organizações: aumentando a competitividade através do intraempreendedorismo. 3. Ed. São Paulo: Saraiva, 2013.

MARCONI, Marina de Andrade e LAKATOS, Eva Maria. Técnicas de pesquisa: Planejamento e execução de pesquisas, amostragens e técnicas de pesquisas, elaboração, análise e interpretação de dados. 5. ed. São Paulo: Atlas, 2002.

MENDONÇA, Mario Jorge. Diagnóstico Das Causas Da Crise Econômica No Brasil e retomada do crescimento econômico. Revista Razão Contábil \& Finanças, v. 9, n. 2, 2019.

MORAIS, Maria Aparecida Silva; FEITOSA FILHO, Raimundo Ivan. A Relevância do Contador para o Microempreendedor Individual (MEI). ID on line REVISTA DE PSICOLOGIA, v. 13, n. 43, p. 480-489, 2019.

PADOVEZE, Clóvis Luís. Contabilidade Gerencial. Curitiba: IESDE Brasil S.A., 2012. p.376.

PORTAL DO EMPREENDEDOR. Estatísticas. 2020. Disponível em: http://www.portaldoempreendedor.gov.br/estatisticas. Acesso em: 26 jan. 2020.

Portal do Empreendedor. MEI. Disponível em: http://www.portaldoempreendedor.gov.br/duvidasfrequentes/6-pagamento-de-obrigacoes-mensais/6.4-caso-o-mei-receba-o-carne-da-cidadaniamas-ja-recolheu-a-guia-de-pagamento-das-como-proceder. Acesso em: 21 fev. 2020.

Portal do Empreendedor: Total de Microempreendedores individuais. Disponível em: http://www.portaldoempreendedor.gov.br/estatisticas. Acesso em 28 jan. 2020

Receita Federal. Receita divulga relação de baixa de CNPJs - MEI. Disponível em: http://receita.economia.gov.br/noticias/ascom/2018/fevereiro/receita-divulga-relacao-de-baixa-decnpjs-do-mei. Acesso em 15 dez. 2019.

Receita Federal. Resolução CGSN n 140 , de 22 de maio de 2018. Regime Especial Unificado de Arrecadação de Tributos e Contribuições devidos pelas Microempresas e Empresas de Pequeno Porte (Simples Nacional). Disponível em: http://normas.receita.fazenda.gov.br/sijut2consulta/link.action?idAto $=92278 \&$ visao $=$ compilado.

Acesso em: 25 jan. 2020.

Rossi Madruga, Sergio; Colossi, Nelson; Biazus, Cleber Augusto Funções e competências gerenciais do contador. Revista de Administração da Universidade Federal de Santa Maria, vol. 9, núm. 2, abril/jun, 2016, pp. 182-191 Universidade Federal de Santa Maria Santa Maria, Brasil. Disponível em: https://www.redalyc.org/articulo.oa?id=273445843001. Acesso em: 20 dez. 2019.

Sebrae. Inadimplência do MEI. 2016. Disponível em: https://datasebrae.com.br/inadimplenciado-mei/. Acesso em: 26 jan. 2020.

SEBRAE. Perfil do MEI. 2018. Disponível em: http://sa.previdencia.gov.br/site/2018/02/Apresenta\%C3\%A7\%C3\%A3o-Aretha-Costa-LagoSEBRAE-_PERFIL-MEI.pdf._Acesso em 25 jan. 2020.

SEBRAE. Perfil do MEI. 2019. Disponível em: https://datasebrae.com.br/perfil-domicroempreendedor-individual/. Acesso em:15 jan. 2020.

SEBRAE. Perfil do MEI. 2019. Disponível em: https://datasebrae.com.br/perfil-domicroempreendedor-individual/\#escolaridade. Acesso em: 24 jan. 2020 
SEBRAE. Perfil do Microempreendedor Individual 2017. Disponível em: https://datasebrae.com.br/wp-content/uploads/2018/03/Perfil-do-Microempreendedor-

Individual_2017-v10.pdf. Acesso em: 25 jan. 2020.

SEBRAE. Quantidade de MEIs aumenta: Saiba mais sobre as vantagens.2019. Disponível em: https://m.sebrae.com.br/sites/PortalSebrae/ufs/pb/artigos/quantidade-de-meis-aumenta-saibamais-sobre-as-vantagens, 1c18e52dfab2a610VgnVCM1000004c00210aRCRD.Acesso em: 10 jan. 2020.

Secretaria da Fazenda. Receita aumenta fiscalização de microempreendedores. 2019. Disponível em: http://www.fazenda.pr.gov.br/modules/noticias/article.php?storyid=963. Acesso em: 07 jan. 2020 .

Serasa Experian. A cada 10 segundos nasce um MEI no Brasil, revela Serasa Experian. 2018. Disponível em: https://www.serasaexperian.com.br/sala-de-imprensa/a-cada-10-segundos-nasceum-mei-no-brasil-revela-serasa-experian. Acesso em: 20 jan. 2020.

SILVA, Ady Júnior Bueno da; MARCELINO, José Antonio. Um Estudo Exploratório Sobre a Atividade de Controladoria e Seu Impacto nas Micro e Pequenas Empresas. Id on Line Rev.Mult. Psic., Outubro/2019, vol.13, n.47, p. 306-319. ISSN: 1981-1179.

SILVA, Airton Marques da. Metodologia da pesquisa. - 2.ed. rev. - Fortaleza, CE: EDUECE, 2015. $108 \quad$ p. 100 Disponível https://200.130.18.160/bitstream/capes/432206/2/Livro_Metodologia\%20da\%20Pesquisa\%20\%20Comum\%20a\%20todos\%20os\%20cursos.pdf. Acesso em: 24 jan. 2020.

Simples Nacional. O que é o Simples Nacional. Disponível em: http://www8.receita.fazenda.gov.br/SimplesNacional/Documentos/Pagina.aspx?id=3. Acesso em 24 jan. 2020.

Simples Nacional. Perguntas e Respostas MEI e Simei. Secretaria-Executiva do Comitê Gestor


http://www8.receita.fazenda.gov.br/SimplesNacional/Arquivos/manual/PerguntaoMEI.pdf. Acesso em: 25 jan. 2020.

VASCONCELLOS FILHO, Paulo de. Análise ambiental para o planejamento estratégico. Revista de Administração de Empresas, v. 19, n. 2, p. 115-127, 1979.

\section{Como citar este artigo (Formato ABNT):}

MARCELINO, José Antonio; SVERZUTI, Aline Rafaela de Oliveira; TRIZOLIO, Bruna Letícia Gomes da Silva. A importância do contador diante do aumento dos índices de microempreendedores individuais inadimplentes: Um estudo nos estados de São Paulo e Paraná. Id on Line Rev.Mult. Psic., Fevereiro/2020, vol.14, n.49, p. 634-651. ISSN: 1981-1179.

Recebido: 26/02/2020;

Aceito: 27/02/2020. 